\title{
PENGARUH BUDAYA KERJA, LINGKUNGAN KERJA DAN INSENTIF TERHADAP MOTIVASI KERJA DAN KINERJA PEGAWAI PADA KANTOR KELURAHAN KABUPATEN BARITO SELATAN
}

\author{
Achmad Mutahir, Ujianto, M. Zaid Abdurrakhman \\ Jl. Ahmad Yani Km. 5.5 Banjarmasin \\ e-mail:mutahirnazfi@gmail.com
}

\begin{abstract}
This research aimed to determine dan analyze the influence of work culture, work environment and incentive on employee performance by work motivation. This quantitative research using path analyis method with intervening variable. Independents variable are work culture, work environment and incentive then dependent variable is employee performance and intervening variable is work motivation. Respondents in the research are using saturated sample technique consist of 120 people. This research using data collection method by questionnaire, interview and direct observation. The method of analysis used in this research is using descriptive and path analysis by AMOS version 23. The result of this research indicated are (1) work culture have positive correlation and significant influence to work motivation; (2) work environment have positive correlation and significant influence to work motivation; (3) incentive have positive correlation and significant influence to work motivation;(4) work culture have positive correlation and significant influence to employee performance; (5) work environment have positive correlation and significant influence to employee performance; (6) incentive have positive correlation and significant influence to employee performance; (7) work motivation have positive correlation and significant influence to employee performance in District Office Of South Barito.
\end{abstract}

Keywords : work culture, work environment, incentive, work motivation, employee performance.

\begin{abstract}
Abstrak: Tujuan penelitian ini adalah untuk mengetahui dan menganalisis pengaruh budaya kerja , lingkungan kerja dan insentif terhadap kinerja pegawai melalui motivasi kerja. Jenis penelitian ini termasuk penelitian kuantitatif dengan metode analisa jalur atau path analysis menggunakan variabel intervening. Variabel independen terdiri dari budaya kerja, lingkungan kerja dan insentif, variabel dependen yaitu kinerja pegawai dan variabel interveningnya yaitu motivasi kerja. Sampel yang digunakan dalam penelitian ini menggunakan teknik sampel jenuh sebanyak 120 orang. Pengumpulan data dilakukan dengan cara menyebarkan kuisioner, wawancara dan observasi langsung. Teknik analisa data menggunakan analisa deskriptif dan analisa jalur (Path Analysis) dengan bantuan program AMOS versi 23. Hasil penelitian menunjukkan bahwa : (1) budaya kerja berpengaruh positif dan signifikan terhadap motivasi kerja; (2) lingkungan kerja berpengaruh positif dan signifikan terhadap motivasi kerja; (3) insentif berpengaruh positif dan signifikan terhadap motivasi kerja; (4) budaya kerja berpengaruh positif dan signifikan terhadap kinerja pegawai; (5) lingkungan kerja berpengaruh positif dan signifikan terhadap kinerja pegawai; (6) insentif berpengaruh positif dan signifikan terhadap kinerja pegawai; (7) motivasi kerja berpengaruh positif dan signifikan terhadap kinerja pegawai pada Kantor Kelurahan Kabupaten Barito Selatan.
\end{abstract}

Kata- kata kunci : budaya kerja, lingkungan kerja, insentif, motivasi kerja, kinerja pegawai. 


\section{PENDAHULUAN}

\subsection{Latar Belakang Masalah}

Di dalam setiap instansi swasta maupun pemerintah termasuk di Kantor Kelurahan Kabupaten Barito Selatan sebagai bagian pemerintahan daerah, tidak akan terlepas dari adanya permasalahan yang berkaitan dengan sumber daya manusia. Peran akan pentingnya sumber daya manusia dalam Kantor Kelurahan merupakan salah satu faktor yang vital bagi pencapaian tujuan visi dan misi Kantor Kelurahan dan pemanfaatan berbagai fungsi di dalam kegiatan manajemen agar efektif dan efisien. Untuk itu sumber daya manusia senantiasa mengadakan integrasi antara kebutuhan, sifat, dan perilaku individu dengan kebutuhannya dan keinginan instansi. Suatu tujuan instansi dapat menentukan berat ringannya tugas, juga dapat digunakan sebagai dasar penyusunan spesifikasi pekerjaan dan berbagai jenis struktur jabatan dalam instansi.

Budaya kerja yang baik akan memberikan landasan kerja yang kuat untuk menjadi budaya prestasi dan merupakan perangkat yang kuat untuk menuntun perilaku kerja dan membantu para pegawai mengerjakan pekerjaan dengan lebih baik, terutama dalam melayani kebutuhan masyarakat dengan sistem dan aturan-aturan yang formal yang memberikan pelayanan kepada masyarakat. Disamping hal-hal tersebut untuk mencapai apa yang telah menjadi tujuan organisasi, kinerja pegawai harus diperhatikan agar selalu berada pada posisi yang tinggi.

Selain itu, Kantor Kelurahan juga harus memperhatikan lingkungan kerja yang ada di sekitar tempat kerja para pegawai termasuk perlengkapan kerja yang memadai yang serba menggunakan teknologi informasi dan peralatan yang memadai terintegrasi dengan berbagai intansi yang berkaitan dengan kantor Kelurahan serta dengan lingkungan kerja yang kondusif, suasana kerja yang harmonis sehingga akan memberikan rasa kebanggaaan bagi setiap pegawai kelurahan Bangkuang. Tersedianya lingkungan kerja yang memadai akan meningkatkan kinerja dan semangat kerja tinggi yang berarti akan meningkatkan pelayanan pada masyarakat. Lingkungan kerja dikatakan mendukung karena tanpa lingkungan kerja yang memadai, maka pekerjaan akan terhambat, terganggu bahkan dapat terhenti sama sekali. Artinya kinerja organisasi ataupun kinerja anggota akan sangat rendah jika anggota dalam melaksanakan tugasnya tidak didukung oleh lingkungan kerja yang kondusif. Namun sebaliknya jika lingkungan kerja kondusif akan berdampak terhadap peningkatan kinerja. Dengan perilaku pegawai yang semakin baik akan menjadi budaya kerja sekaligus menjadi budaya organisasi yang kuat dan berkelanjutan.

Menurut Dessler (1995:411) "insentif adalah ganjaran financial yang diberikan kepada karyawan yang tingkat produksinya melampaui standar yang telah ditetapkan sebelumnya. Sedangkan menurut Moekijat (1991:124) "insetif yang berbentuknya sederhana adalah standar potongan yang menghubungkan pendapatan dengan produktivitasdan dapat menggunakan premi, bonus atau bermacam-macam standar untuk memberikan imbalan jasa kepada pelaksanaan yang lebih baik."

Faktor lain yang diidentifikasi mempengaruhi kinerja pegawai adalah motivasi. Motivasi merupakan usaha sadar untuk mempengaruhi perilaku seseorang agar mengarah pada tercapainya tujuan organisasi yang telah ditentukan. Motivasi menjadi sangat penting dalam pencapaian kinerja pegawai. Motivasi berdampak pada seseorang atau individu untuk melibatkan diri pada kegiatan dan pekerjaan yang mengarah pada tujuan sebagai kepuasan. Pegawai memiliki keinginan yang kuat yang muncul akibat adanya dorongan dari dalam diri 
untuk terlibat serta berpartisipasi dalam organisasi dengan mengerjakan segala tugas dan pekerjaan yang dibebankan dan secara berkelanjutan pegawai akan terus mendedikasikan diri melalui segala tugas dan pekerjaan secara sukarela karena kenyamanan serta rasa senang yang didasari motivasi yang kuat.

Berdasarkan uraian yang telah diberikan tersebut di atas maka peneliti tertarik untuk mengambil peenlitian yang berjudul "Pengaruh Budaya Kerja, Lingkungan Kerja dan Insentif terhadap Motivasi Kerja dan Kinerja Pegawai Pada Kantor Kelurahan Kabupaten Barito Selatan.

\subsection{Rumusan Masalah}

Berdasarkan latar belakang di atas, maka perumusan masalah dalam penelitian ini adalah :

a. Apakah budaya kerja berpengaruh signifikan terhadap motivasi kerja pada Kantor Kelurahan Kabupaten Barito Selatan? $\begin{array}{lrr}\text { b. Apakah } & \text { lingkungan } & \text { kerja } \\ \text { berpengaruh } & \text { signifikan } & \text { terhadap } \\ \text { motivasi } & \text { kerja pada } & \text { Kantor } \\ \text { Kelurahan } & \text { Kabupaten } & \text { Barito } \\ \text { Selatan? } & & \end{array}$

c. Apakah insentif berpengaruh signifikan terhadap motivasi kerja pada Kantor Kelurahan Kabupaten Barito Selatan?

d. Apakah budaya kerja berpengaruh signifikan terhadap kinerja pegawai pada Kantor Kelurahan Kabupaten Barito Selatan?

\section{e. Apakah lingkungan kerja berpengaruh signifikan terhadap kinerja pegawai pada Kantor Kelurahan Kabupaten Barito Selatan?}

f. Apakah insentif berpengaruh signifikan terhadap kinerja pegawai pada Kantor Kelurahan Kabupaten Barito Selatan?

g. Apakah motivasi kerja berpengaruh signifikan terhadap kinerja pegawai pada Kantor Kelurahan Kabupaten Barito Selatan?

\subsection{Tujuan Penelitian}

a. Mengetahui dan menganalisis pengaruh budaya kerja terhadap motivasi kerja pada Kantor Kabupaten Barito Selatan.

b. Mengetahui dan menganalisis pengaruh lingkungan kerja terhadap motivasi kerja pada Kantor Kabupaten Barito Selatan.

c. Mengetahui dan menganalisis pengaruh insentif terhadap motivasi kerja pada Kantor Kabupaten Barito Selatan.

d. Mengetahui dan menganalisis pengaruh budaya kerja terhadap kinerja pegawai pada Kantor Kabupaten Barito Selatan.

e. Mengetahui dan menganalisis pengaruh lingkungan kerja terhadap kinerja pegawai pada Kantor Kabupaten Barito Selatan.

f. Mengetahui dan menganalisis pengaruh insentif terhadap kinerja pegawai pada Kantor Kabupaten Barito Selatan.

g. Mengetahui dan menganalisis pengaruh motivasi kerja terhadap kinerja pegawai pada Kantor Kabupaten Barito Selatan.

\section{TINJAUAN PUSTAKA}

\subsection{Kinerja Pegawai}

Menurut kamus besar bahasa Indonesia (2005) "kerja diartikan sebagai kegiatan untuk melakukan sesuatu yang dilakukan atau diperbuat dan sesuatu yang dilakukan untuk mencari nafkah, mata pencaharian". Menurut B. Renita (2006) kerja dipandang dari sudut sosial merupakan kegiatan yang dilakukan dalam upaya untuk mewujudkan kesejahteraan umum, terutama bagi orangorang terdekat (keluarga) dan masyarakat, untuk mempertahankan dan mengembangkan kehidupan, sedangkan dari sudut rohani atau religius, kerja adalah suatu upaya untuk mengatur dunia sesuai dengan kehendak Sang Pencipta. Dalam hal ini, bekerja merupakan suatu 
komitmen hidup yang harus dipertangungjawabkan kepada Tuhan.

Menurut Robbins (2012:187) kinerja diartikan sebagai fungsi dari interaksi antara kemampuan (ability) dan motivasi (motivation) sehingga kinerja $=\mathrm{f}(\mathrm{A} \times \mathrm{M})$.Jika ada yang tidak memadai, kinerja itu akan dipengaruhi secara negatif. Menurut Amstrong dan Baron dalam Wibowo (2009) kinerja merupakan hasil pekerjaan yang mempunyai hubungan kuat dengan tujuan strategis organisasi, kepuasan konsumen dan memberikan kontribusi ekonomi.

Kinerja mempunyai arti yang lebih luas, bukan hanya menyatakan sebagai hasil kerja tetapi juga bagaimana proses kerja berlangsung. Selain itu, kinerja juga merupakan hasil dari efisiensi pengelolaan masukan dan efektivitas pencapaian sasaran. Oleh karena itu, efektivitas dan efisiensi pekerjaan yang tinggi akan menghasilkan kinerja yang tinggi pula. Untuk memperoleh kinerja yang tinggi dibutuhkan sikap mental yang memiliki pandangan jauh ke depan. Seseorang harus mempunyai sikap optimis, bahwa kualitas hidup dan kehidupan hari esok lebih baik dari hari ini. Dessler (2006) berpendapat bahwa kinerja karyawan merupakan prestasi kerja, yakni perbandingan antara hasil kerja yang dapat dilihat secara nyata dengan standar kerja yang telah ditetapkan organisasi. Jadi, dapat disimpulkan bahwa kinerja adalah perbandingan antara hasil kerja yang dapat dilihat secara nyata dengan standar kerja yang telah ditetapkan organisasi.

\subsection{Budaya Kerja}

Budaya kerja merupakan media untuk mengubah cara kerja lama menjadi cara kerja baru yang berorientasi pada upaya memuaskan pelanggan atau masyarakat.
Kualitas atau mutu suatu produk barang atau jasa, cara kerja dan tenaga kerja harus dapat diukur. Pengukuran kualitas, antara lain aspek persyaratan, bentuk warna, estetika, ketahanan, performa, waktu, jaminan dan pelayanan.

Budaya kerja adalah suatu falsafah yang didasari oleh pandangan hidup sebagai nilai yang menjadi sifat, kebiasaan dan kekuatan mendorong, membudaya dalam kehidupan suatu kelompok masyarakat atau organisasi, kemudian tercermin dari sikap menjadi perilaku, kepercayaan, citacita, pendapat dan tindakan yang terwujud sebagai kerja atau bekerja (Umam.2018). Budaya kerja organisasi adalah manajemen yang meliputi pengembangan, perencanaan, produksi dan pelayanan suatu produk yang berkualitas dalam arti optimal, ekonomis dan memuaskan. Budaya kerja berbeda dengan budaya organisasi, sedangkan pengertian budaya organisasi, Sedarmayanti (2007) menyatakan bahwa "Budaya organisasi adalah sebuah keyakinan, sikap dan nilai yang umumnya dimiliki, yang timbul dalam organisasi". Wheelen dan Hunger (2002:45) berpendapat bahwa budaya organisasi adalah himpunan dari kepercayaan, harapan, dan nilai-nilai yang dianut bersama oleh anggota perusahaan dan diwariskan dari suatu generasi ke generasi berikutnya.

Jadi budaya organsiasi dapat didefinisikan sebagai apa yang biasa dilakukan di dalam perusahaan, mencakup bagaimana perusahaan memproduksi produk, membayar hutang, memperlakukan karyawannya, maupun melakukan kegiatan operasional organisasi lainnya, sedangkan budaya kerja merubah perilaku menjadi budaya kerja.

\subsection{Lingkungan Kerja}


Lingkungan kerja adalah tempat di mana pegawai melakukan aktivitas setiap harinya. Lingkungan kerja yang kondusif memberikan rasa aman dan memungkinkan pegawai untuk dapat bekerja optimal. Lingkungan kerja dapat mempengaruhi emosi pegawai. Jika pegawai menyenangi lingkungan kerja di mana dia bekerja, maka pegawai tersebut akan betah di tempat kerjanya, melakukan aktivitas sehingga waktu kerja dipergunakan secara efektif. Produktivitas akan tinggi dan optimis prestasi kerja pegawai juga tinggi. Lingkungan kerja itu mencakup hubungan kerja yang terbentuk antara sesama pegawai dan hubungan kerja antar bawahan dan atasan serta lingkungan fisik tempat pegawai bekerja.

Menurut Nitisemito (2004 : 200) mendefenisikan lingkungan kerja sebagai berikut : "Lingkungan kerja adalah sesuatu yang ada di sekitar para pekerja yang dapat mempengaruhi dirinya dalam menjalankan tugas-tugas yang diembankan". Menurut Sedarmayati (2004 : 89) mendefinisikan lingkungan kerja sebagai berikut : "Lingkungan kerja adalah keseluruhan alat perkakas dan bahan yang dihadapi, lingkungan sekitarnya di mana seseorang bekerja, metode kerjanya, serta pengaturan kerjanya baik sebagai perseorangan maupun sebagai kelompok".

Lebih lanjut Gitosudarmo dalam Sujadi (2007 : 19), menyatakan bahwa lingkungan kerja terdiri dari lingkungan fisik dan lingkungan organisasi yang menjadikan iklim kerja positif. Hal senada juga dinyatakan oleh Kaho dalam Sujadi (2007 : 19), bahwa dalam persiapan otonomi daerah perlu didukung oleh lingkungan kerja yang kondusuf berupa ketersediaan sumber daya non manusia seperti; kendaraan, gedung, peralatan, materi dan lainlain. Hal yang sama juga dikatakan Sutermeister dalam Sujadi (2007 : 19), bahwa indikator lingkungan kerja merupakan physical condition yang meliputi lighting, temperature, ventillation, rest period, safety, dan suasana kerja.

Dari beberapa pendapat tersebut dapat disimpulkan bahwa lingkungan kerja adalah segala sesuatu yang ada di sekitar para pekerja, yang keberadaannya penting untuk membangkitkan semangat dan gairah kerja karyawan dalam menjalankan tugas seharihari, terutama dalam menunjang tingkat kinerja karyawan. Dan lingkungan kerja merupakan segala sesuatu yang ada di sekitar karyawan pada saat bekerja, baik yang berbentuk fisik ataupun non fisik, langsung atau tidak langsung, yang dapat mempengaruhi dirinya dan pekerjaanya saat bekerja.

\subsection{Insentif}

Pada dasarnya, setiap orang ingin bekerja dengan baik. Hanya saja harus diakui tidak semua orang dapat bekerja dengan baik. Diantara pekerja yang diterima bekerja dalam suatu perusahaan yang telah diseleksi sebelum diterima akan menunjukkan produktivitas kerja yang sama, hal ini disebabkan oleh faktor-faktor seperti : pendidikan dan pengalaman, tingkat kerajinan atau kurangnya motivasi yang diberikan adalah merupakan tanggung jawab perusahaan dengan demikian rendahnya produktivitas kerja seseorang atau keseluruhan pekerja yang diakibatkan oleh kurangnya motivasi kerja yang harus segera diatasi oleh perusahaan. Alat motivasi yang umum diberikan oleh perusahaan untuk mendorong dan merangsang pegawai agar semangat bekerja untuk mendapatkan kepuasan kerja pegawai adalah insentif.

Hasibuan (2006) memberikan definisi sebagai berikut : "Insentif adalah daya perangsang yang diberikan 
kepada Pegawai tertentu berdasarkan prestasi kerjanya agar pegawai terdorong meningkatkan prestasi kerjanya". Martoyo (2008), menyatakan bahwa "Insentif adalah memberikan upah/gaji yang berbeda, tetapi bukan didasarkan pada evaluasi jabatan, namun ditentukan karena perbedaan prestasi kerja".

Menurut Harianja (2009) bahwa : "Insentif diartikan sebagai bentuk pembayaran langsung yang didasarkan atau dikaitkan langsung dengan kinerja dan gain sharing yang juga dikaitkan dengan kinerja dan diartikan sebagai pembagian keuntungan bagi pegawai akibat peningkatan produktivitas atau penghematan biaya". Sarwoto (2006) menyatakan bahwa "Insentif ialah sarana motivasi, dapat berupa perangsang atau pendorong yang diberikan dengan sengaja kepada para pekerja agar dalam diri mereka timbul semangat yang lebih besar untuk berprestasi bagi perusahaan".

Berdasarkan beberapa pengertian di atas, dapat disimpulkan bahwa insentif merupakan suatu lembaga untuk memberikan daya perangang kepada pegawainya dalam tugas yang diberikan kepadanya. Jadi pada pengertian ini insentif merupakan suatu cara atau sarana untuk menggerakkan tenaga kerja agar melakukan tugasnya sehingga apa yang dituju oleh instansi atau organisasi dapat diraih dengan baik.

\subsection{Motivasi Kerja}

Menurut Hasibuan (2000:105) Abraham Sperling dalam Mangkunegara

mengemukakan bahwa: "Motive is defined as a tendency to activity, started by a drive andended by an adjustment. The adjustment is said to satisfy themotive". (Motif didefinisikan sebagai suatu kecenderungan untuk beraktivitas, dimulai dari dorongan dalam diri (drive) dan diakhiri dengan penyesuaian diri. Penyesuaian diri dikatakan untuk memuaskan motif).
William J.

Stanton dalam Hasibuan (2012) mendefinisikan bahwa: "A motive is a stimulated need which a goaloriented individualseeks to satisfy". (Suatu motif adalah kebutuhan yang distimulasiyang berorientasi kepada tujuan individu dalam mencapai rasa puas). Selain itu, motivasi didefinisikan oleh Stanford dalam Hasibuan (2012) bahwa: "Motivation as an energizing condition of the organism that serves to direct that organism toward the goal of a certain class". (Motivasi sebagai suatu kondisi yang menggerakkan manusia ke arah suatu tujuan tertentu). Motif merupakan suatu dorongan kebutuhan dalam diri karyawan yang perlu dipenuhi agar karyawan tersebut dapat menyesuaikan diri terhadap lingkungannya, sedangkan motivasi adalah kondisi yang menggerakkan karyawan agar mampu mencapai tujuan dari motifnya. Pemimpin perlu memahami apa saja yang dapat meningkatkan motivasi pengikutnya yang memiliki dampak pada kinerja yang dirasakan. Hal ini dapat dikritisi sejak tahap seleksi karyawan baru, dimana pemimpin dapat menganalisis motivasi calon karyawan dengan seksama sehingga akan tepat dalam proses penempatan karyawan (Miao et al, 2007). Motivasi intrinsik didefinisikan sebagai "kesenangan atau nilai dari suatu kegiatan itu sendiri", sementara motivasi ekstrinsik "menekankan nilai dari suatu tempat individu pada hasil dari suatu tindakan dan penilaian individu itu sendiri dari kemungkinan pencapaian hasil.

Berdasarkan penelitian psikologi sosial yang dilakukan oleh Amabile (1994) dalam Miao et al (2007), motivasi instrinsik dan ekstrinsik terdiri dari dimensi kognitif dan afektif. 


\section{HIPOTESIS}

1. Variabel budaya kerja berpengaruh signifikan terhadap motivasi kerja pada Kantor Kelurahan Kabupaten Barito Selatan.

2. Variabel lingkungan kerja berpengaruh signifikan terhadap motivasi kerja pada Kantor Kelurahan Kabupaten Barito Selatan.

3. Variabel insentif berpengaruh signifikan terhadap kepuasan kerja pada Kantor Kelurahan Kabupaten Barito Selatan.

4. Variabel budaya kerja berpengaruh signifikan terhadap kinerja pegawai pada Kantor Kelurahan Kabupaten Barito Selatan.

5. Variabel lingkungan kerja berpengaruh signifikan terhadap kinerja pegawai pada Kantor Kelurahan Kabupaten Barito Selatan.

6. Variabel lingkungan kerja berpengaruh signifikan terhadap kinerja pegawai pada Kantor Kelurahan Kabupaten Barito Selatan.

7. Variabel motivasi kerja berpengaruh signifikan terhadap kinerja pegawai pada Kantor Kelurahan Kabupaten Barito Selatan.

\section{METODE PENELITIAN}

\subsection{Jenis penelitian}

Penelitian ini menggunakan pendekatan kuantitatif. Penelitian ini menggunakan pendekatan kuantitatif dalam usaha menguji hipotesis yang telah disusun. Jenis penelitian ini menggunakanpendekatan korelasional. Pendekatan korelasional adalah jenis penelitian yang bertujuan untuk menemukan ada atau tidak adanya hubungan antara dua atau lebih dari variabel yang akan diukur, bila terdapat hubungan maka berapa eratnya hubungan serta berarti atau tidaknya hubungan itu.

\subsection{Variabel Penelitian}

Variabel independen terdiri dari budaya kerja, lingkungan kerja dan insentif sedangkan variabel dependen yaitu kinerja pegawai dan variabel interveningnya yaitu motivasi kerja.

\subsection{Populasi dan Sampel}

Populasi dalam penelitian ini adalah Populasi dalam penelitian ini adalah para pegawai pada Kantor Kelurahan Kabupaten Barito Selatan.

Teknik pengambilan sampel dalam penelitian ini menggunakan teknik sampel jenuh atau sensus, yaitu semua populasi menjadi sampel penelitian (Sugiyono, 2006 : 78). Ukuran sampel memegang peran penting dalam estimasi dan intepretasi hasil SEM. Hair dkk dalam Ferdinand (2002) menemukan bahwa ukuran sampel yang sesuai adalah antara 100 200. Ukuran sampel minimum adalah sebanyak 5 obsevasi (indikator) untuk setiap estimated parameter (variabel). Bila estimated parameter berjumlah 20, maka jumlah sampel sebanyak 100. Tergantung pada jumlah indikator yang digunakan dalam seluruh variabel laten. Jumlah sampel adalah jumlah indikator dikali 5 sampai 10. Bila terdapat 20 indikator maka besarnya atau jumlah sampel antara 100 - 200. Dalam penelitian ini jumlah indikator sebanyak 24 indikator, sehingga jumlah sampel 24 dikali 5 adalah sebanyak 120 sampel.

Jadi, sampel dalam penelitian ini adalah seluruh pegawai tetap dan pegawai honorer di Kantor Kelurahan Kabupaten Barito Selatan sebanyak 120 orang.

\subsection{Teknik Analisa Data}

Teknik pengumpulan data menggunakan survey lapangan/ observasi langsung, kuisioner dan studi kepustakaan. Teknik analisa data menggunakan analisa deskriptif dan analisa jalur (Path Analysis) dengan bantuan SEM AMOS versi 23.

\subsection{Lokasi Penelitian}

Lokasi penelitian berada di wilayah Kabupaten Barito Selatan, Provinsi Kalimantan Tengah. Lokasi penelitian masih dalam jangkauan peneliti sehingga masih memudahkan peneliti untuk penarikan sampel penelitian. 
ANALISIS HASIL PENELITIAN DAN PEMBAHASAN

1. Karakteristik Berdasarkan Jenis Kelamin.

\begin{tabular}{|l|c|c|}
\hline JenisKelamin & Jumlah & \% \\
\hline \multicolumn{1}{|c|}{$(\mathbf{1})$} & $\mathbf{( 2 )}$ & $\mathbf{( 3 )}$ \\
\hline Laki-laki & 80 & 66.7 \\
\hline Perempuan & 40 & 33.3 \\
\hline Total & $\mathbf{1 2 0}$ & $\mathbf{1 0 0}$ \\
\hline
\end{tabular}

2. Karakteristik Responden

Berdasarkan Usia.

\begin{tabular}{|l|c|c|}
\hline JenisKelamin & Jumlah & \% \\
\hline (1) & $(\mathbf{2})$ & $\mathbf{( 3 )}$ \\
\hline 17-27 Tahun & 25 & 20.8 \\
\hline 28-37 Tahun & 55 & 45.8 \\
\hline > 37 Tahun & 40 & 33.4 \\
\hline Total & $\mathbf{1 2 0}$ & $\mathbf{1 0 0}$ \\
\hline
\end{tabular}

3. Karakteristik

Responden

Berdasarkan Tingkat Pendidikan

\begin{tabular}{|c|c|c|}
\hline Pendidikan & Jumlah & \% \\
\hline (1) & $\mathbf{( 2 )}$ & $\mathbf{( 3 )}$ \\
\hline SMA/SMK & 51 & 42.5 \\
\hline Diploma 3 & 35 & 29.2 \\
\hline Sarjana & 24 & 17.5 \\
\hline Pasca Sarjana & 10 & 10.8 \\
\hline Total & $\mathbf{1 2 0}$ & $\mathbf{1 0 0}$ \\
\hline
\end{tabular}

4. Karakteristik

Berdasarkan Lama Bekerja.

\begin{tabular}{|c|c|c|}
\hline Pendidikan & Jumlah & \% \\
\hline (1) & $\mathbf{( 2 )}$ & $\mathbf{( 3 )}$ \\
\hline 1-5 Tahun & 51 & 42.5 \\
\hline 6-10 Tahun & 42 & 35 \\
\hline >10 Tahun & 48 & 40 \\
\hline Total & $\mathbf{1 2 0}$ & $\mathbf{1 0 0}$ \\
\hline
\end{tabular}

Analisis Hasil Penelitian

1. Hasil Uji Validitas dan Reliabilitas

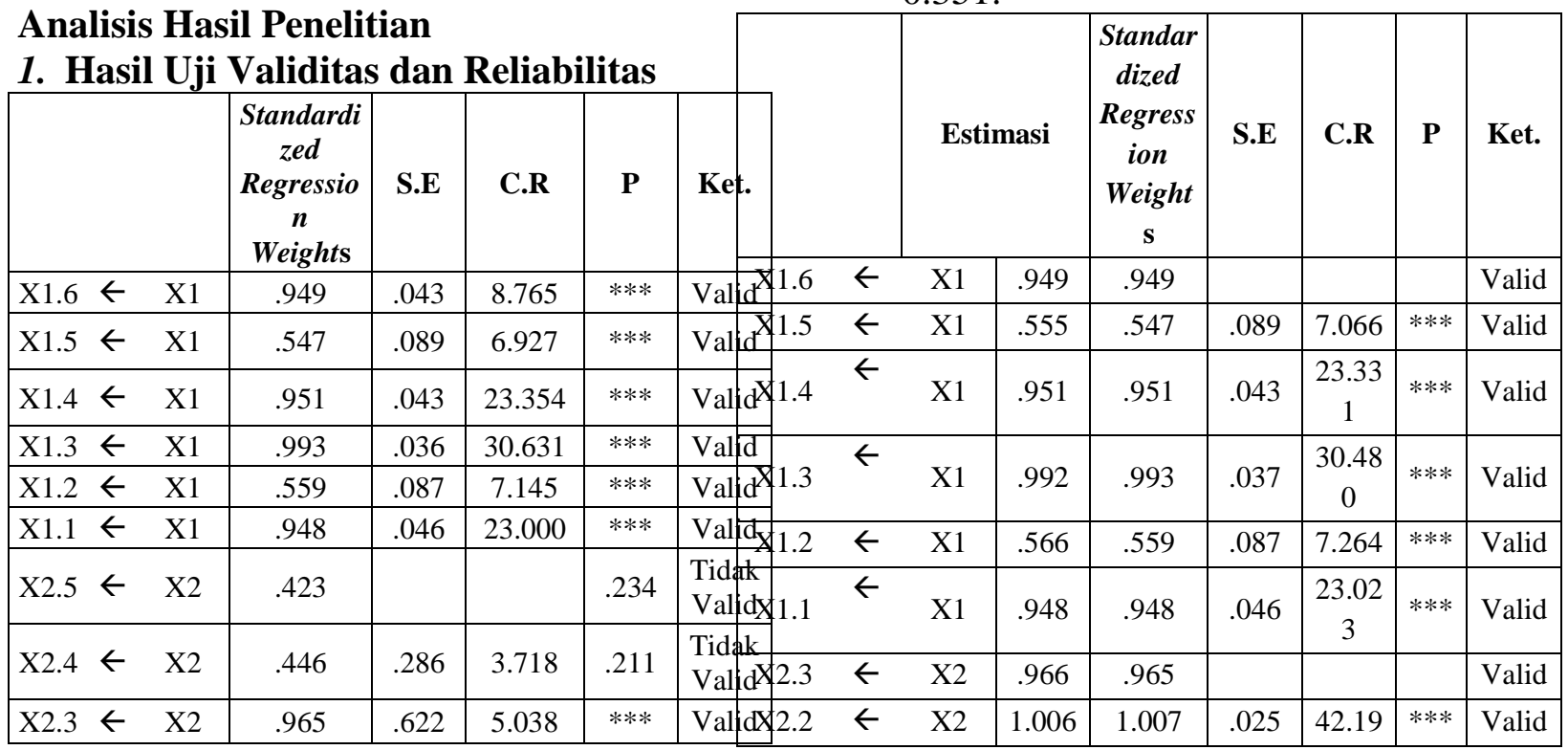

\begin{tabular}{|c|c|c|c|c|c|}
\hline $\mathrm{X} 2.2 \leftarrow \mathrm{X} 2$ & .1 .007 & .666 & 5.015 & $* * *$ & Valid \\
\hline $\mathrm{X} 2.1 \leftarrow \mathrm{X} 2$ & .651 & .474 & 4.482 & $* * *$ & Valid \\
\hline $\mathrm{X} 3.3 \leftarrow \mathrm{X} 3$ & .729 & .127 & 7.685 & $* * *$ & Valid \\
\hline $\mathrm{X} 3.2 \leftarrow \mathrm{X} 3$ & .509 & .172 & 4.072 & $* * *$ & Valid \\
\hline $\mathrm{X} 3.1 \leftarrow \mathrm{X} 3$ & .535 & .252 & 3.885 & $* * *$ & Valid \\
\hline $\mathrm{Z} 1.5 \leftarrow$ & .359 & & & & $\begin{array}{l}\text { Tidak } \\
\text { Valid }\end{array}$ \\
\hline $\mathrm{Z} 1.4 \leftarrow$ & .965 & .492 & 4.881 & $* * *$ & Valid \\
\hline $\mathrm{Z} 1.3 \leftarrow$ & .379 & .293 & 3.567 & $* * *$ & Valid \\
\hline $\mathrm{Z} 1.2 \leftarrow$ & .662 & .392 & 4.497 & $* * *$ & Valid \\
\hline $\mathrm{Z} 1.1 \leftarrow$ & 1.003 & .509 & 4.908 & $* * *$ & Valid \\
\hline $\mathrm{Y} 1.1 \leftarrow$ & 1.001 & & & & Valid \\
\hline $\mathrm{Y} 1.2 \leftarrow$ & .640 & .066 & 10.035 & $* * *$ & Valid \\
\hline $\mathrm{Y} 1.3 \leftarrow$ & .993 & .009 & 11.745 & $* * *$ & Valid \\
\hline $\mathrm{Y} 1.4 \leftarrow$ & .426 & .069 & 5.667 & $* * *$ & $\begin{array}{l}\text { Tidak } \\
\text { Valid }\end{array}$ \\
\hline $\mathrm{Y} 1.5 \leftarrow$ & .351 & .089 & 4.511 & $* * *$ & $\begin{array}{l}\text { Tidak } \\
\text { Valid }\end{array}$ \\
\hline
\end{tabular}

Berdasarkan hasil analisis yang disajikan tabel diatas, terdapat indikator yang menunjukkan hasil yang belum memenuhi syarat dengan nilai C.R. > 1,96 dan nilai standardized regression estimate $>0,5$ yaitu X2.4 dengan nilai standardized regression estimate $0.446, \quad \mathrm{X} 2.5$ dengan nilai standardized regression estimate $0.423, \mathrm{Z} 1.3$ dengan nilai standardized regression estimate $0.379, \mathrm{Z} 1.5$ dengan nilai standardized regression estimate $0.359, \quad \mathrm{Y} 1.4$ dengan nilai standardized regression estimate 0.426, dan Y1.5 dengan nilai standardized regression estimate 0.351 . 


\begin{tabular}{|lll|l|l|l|c|c|c|}
\hline & & & & & & 5 & & \\
\hline $\mathrm{X} 2.1$ & $\leftarrow$ & $\mathrm{X} 2$ & .645 & .651 & .074 & 9.014 & $* * *$ & Valid \\
\hline $\mathrm{X} 3.3$ & $\leftarrow$ & $\mathrm{X} 3$ & .506 & .729 & & & & Valid \\
\hline $\mathrm{X} 3.2$ & $\leftarrow$ & $\mathrm{X} 3$ & .687 & .509 & .290 & 3.290 & $\begin{array}{c}.00 \\
1\end{array}$ & Valid \\
\hline $\mathrm{X} 3.1$ & $\leftarrow$ & $\mathrm{X} 3$ & .952 & .535 & .671 & 4.658 & $* * *$ & Valid \\
\hline $\mathrm{Z} 1.4$ & $\leftarrow$ & $\mathrm{Z}$ & .974 & .965 & .492 & 4.881 & $* * *$ & Valid \\
\hline $\mathrm{Z} 1.2$ & $\leftarrow$ & $\mathrm{Z}$ & .716 & .662 & & & & Valid \\
\hline $\mathrm{Z} 1.1$ & $\leftarrow$ & $\mathrm{Z}$ & 1.003 & 1.003 & .067 & $\begin{array}{c}10.92 \\
0\end{array}$ & $* * *$ & Valid \\
\hline $\mathrm{Y} 1.1$ & $\leftarrow$ & $\mathrm{Y}$ & 1.001 & 1.001 & & & & Valid \\
\hline $\mathrm{Y} 1.2$ & $\leftarrow$ & $\mathrm{Y}$ & .677 & .640 & .066 & $\begin{array}{c}10.05 \\
9\end{array}$ & $* * *$ & Valid \\
\hline $\mathrm{Y} 1.3$ & $\leftarrow$ & $\mathrm{Y}$ & .994 & .993 & .009 & $\begin{array}{c}110.0 \\
72\end{array}$ & $* * *$ & Valid \\
\hline
\end{tabular}

1. Hasil analisa jalur dapat dilihat nilai C.R sebesar 13.061 yang berarti arah hubungan positif dan nilai $P$-Value variabel budaya kerja $\left(\mathrm{X}_{1}\right)$ adalah sebesar 0.000 lebih kecil dari 0.050 yang berarti berpengaruh signifikan. Dengan demikian dapat disimpulkan hipotesa 1 (satu) diterima bahwa budaya kerja berpengaruh positif dan signifikan terhadap motivasi kerja pada Kantor Kelurahan Kabupaten Barito Selatan.

2. Hasil analisa jalur dapat dilihat nilai $C . R$ sebesar 2.193 yang berarti arah hubungan positif dan nilai $P$-Value variabel lingkungan kerja $\left(\mathrm{X}_{2}\right)$ adalah sebesar 0.028 lebih kecil dari 0.050 yang berarti berpengaruh signifikan. Dengan demikian dapat disimpulkan hipotesa 2 (dua) diterima bahwa lingkungan kerja berpengaruh positif dan signifikan terhadap terhadap motivasi kerja pada Kantor Kelurahan Kabupaten Barito Selatan.

3. Hasil analisa jalur dapat dilihat nilai C.R sebesar 2.248 yang berarti arah hubungan positif dan nilai $P$-Value variabel tantangan tugas $\left(\mathrm{X}_{3}\right)$ adalah sebesar 0.015 lebih kecil dari 0.050 yang berarti berpengaruh signifikan. Dengan demikian dapat disimpulkan hipotesa 3 (tiga) diterima bahwa insentif berpengaruh positif dan signifikan terhadap terhadap motivasi kerja pada Kantor Kelurahan Kabupaten Barito Selatan.

4. Hasil analisa jalur dapat dilihat nilai C.R sebesar 2.972 yang berarti arah hubungan positif dan nilai $P$-Value variabel budaya kerja $\left(\mathrm{X}_{1}\right)$ adalah

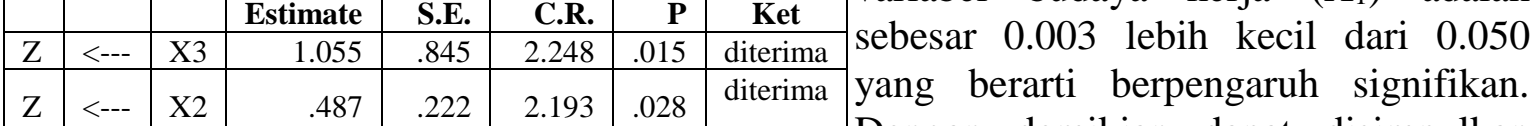

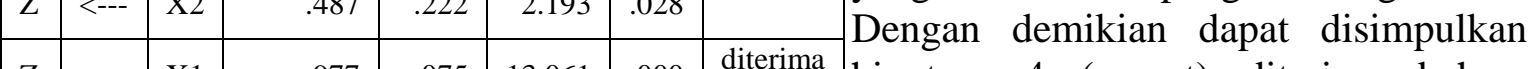

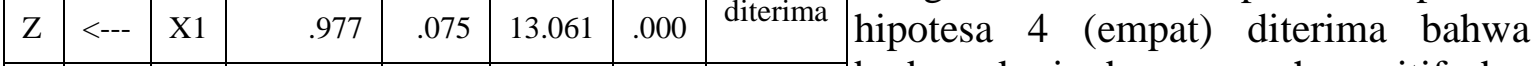
\begin{tabular}{|l|l|l|l|l|l|l|l}
\hline $\mathrm{Y}$ & $<---$ & $\mathrm{X} 1$ & .631 & .212 & 2.972 & .003 & diterima \\
budaya kerja berpengaruh positif dan
\end{tabular}

\begin{tabular}{|r|l|l|r|r|r|r|r|r|}
\hline $\mathrm{Y}$ & $<--$ & $\mathrm{X} 2$ & .390 & .356 & 2.895 & .035 & diterima & ter \\
\hline $\mathrm{Y}$ & $<---$ & $\mathrm{X} 3$ & 1.306 & 1.247 & 2.123 & .024 & $\begin{array}{r}\text { diterima } \\
\text { 6. }\end{array}$ \\
\hline $\mathrm{Y}$ & $<---$ & $\mathrm{Z}$ & .503 & .147 & 3.423 & .000 & diterima \\
\hline
\end{tabular}
signifikan terhadap kinerja pegawai terhadap motivasi kerja pada Kantor Kelurahan Kabupaten Barito Selatan.

Hasil analisa jalur dapat dilihat nilai C.R sebesar 2.895 yang berarti arah hubungan positif dan nilai $P$-Value variabel lingkungan kerja $\left(\mathrm{X}_{2}\right)$ adalah Pengaruh Langsung sebesar 0.035 lebih kecil dari 0.050 
yang berarti berpengaruh signifikan. Dengan demikian dapat disimpulkan hipotesa 5 (lima) diterima bahwa lingkungan kerja berpengaruh positif dan signifikan terhadap kinerja pegawai pada Kantor Kelurahan Kabupaten Barito Selatan.

7. Hasil analisa jalur dapat dilihat nilai C.R sebesar 2.123 yang berarti arah hubungan positif dan nilai $P$-Value variabel insentif $\left(\mathrm{X}_{3}\right)$ adalah sebesar 0.024 lebih kecil dari 0.050 yang berarti berpengaruh signifikan. Dengan demikian dapat disimpulkan hipotesa 6 (enam) diterima bahwa insentif berpengaruh positif dan signifikan terhadap kinerja pegawai pada Kantor Kelurahan Kabupaten Barito Selatan.

8. Hasil analisa jalur dapat dilihat nilai C.R sebesar 3.423 yang berarti arah hubungan positif dan nilai $P$-Value variabel tantangan tugas $\left(\mathrm{X}_{3}\right)$ adalah sebesar 0.000 lebih kecil dari 0.050 yang berarti berpengaruh signifikan. Dengan demikian dapat disimpulkan hipotesa 7 (tujuh) diterima bahwa motivasi kerja berpengaruh positif dan signifikan terhadap kinerja pegawai di Kabupaten Barito Selatan.

\section{KESIMPULAN DAN SARAN}

a. Budaya kerja pada Kantor Kelurahan Kabupaten Barito Selatan saat ini sangat baik dalam menunjang motivasi dan sistim kerja para pegawainya, Namun tetap perlu dipertahankan bahkan dioptimalisasikan kondisi yang ada untuk peningkatkan produktivitas para pegawainya.

b. Lingkungan kerja yang dimiliki dan di ciptakan pada Kantor Kelurahan Kabupaten Barito Selatan masih dirasa perlu ditingkatkan dan dimaksimalkan untuk menunjang kinerja pegawainya dalam bekerja. Walaupun lingkungan kerja yang dirasakan para pegawai sudah nyaman dalam bekerja. Alangkah lebih baik lagi juga itu tetap dipertahankan dan bila perlu dilengkapi dengan fasilitas yang menunjang para pegawai dalam bekerja. Untuk mengetahui kekurangan fasilitas yang dimiliki, Kantor Kelurahan Kabupaten Barito Selatan perlu mengkaji dan menganalisa konsep kebutuhan pengadaan fasilitas kerja kantor sehingga dapat diusulkan kepada pimpinan.

c. Insentif yang diterima para pegawai pada Kantor Kelurahan Kabupaten Barito Selatan masih belum maksimal perolehannya dikarenakan belum sesuai dengan ketetapan UMR yang disahkan oleh Pemerintah Daerah. Untuk mengetahui memaksimalkan pendapatan pegawai, Kantor Kelurahan Kabupaten Barito Selatan perlu mengkaji dan menganalisa insentif yang seharusnya diberikan untuk setiap pegawai sehingga dapat diusulkan kepada pimpinan kantor.

d. Untuk penelitian selanjutnya, peneliti mengharapkan untuk dapat mengembangkan penelitian terutama penelitian menggunakan variabel lainnya seperti fungsi kepemimpinan, disiplin kerja, kemampuan kerja, kompensasi dan pelatihan ataupun variabel lainnya yang mendukung terhadap motivasi kerja dan kinerja pegawai dimasa yang akan datang.

\section{DAFTAR PUSTAKA.}

Gibson, James L, dan Ivancevich, John M dan Donnely Jr, James H, 1995. Organisasi dan Manajemen. Terjemahan. Jakarta : PT. Erlangga

Ghozali, Imam, 2001, Aplikasi Analisis Multivariate Dengan Program AMOS, Edisi II, Penerbit Badan Penerbit Universitas Diponegoro, Semarang.

Hasibuan, Malayu SP. 2012. Manajemen Sumber Daya Manusia. Edisi Revisi. Jakarta: PT Bumi Aksara.

Luthans, Fred. 2006., Perilaku Organisasi 10th. Edisi Indonesia. Yogyakarta: Penerbit ANDI.

Mangkunegara, A.A Anwar Prabu. 2015, Manajemen Sumber Daya Manusia Perusahaan, Penerbit Bandung : Remaja Rosdakarya

Mangkunegara Anwar Prabu A.A, 2003, Perencanaan dan Pengembangan 
Sumber Daya Manusia, Cetakan Pertama, PT Refika Aditama, Bandung.

Manulang, M, 2006. Manajemen Sumber Daya Manusia, Penerbit BPFE, Yogyakarta.

Moenir, 2002, Pengembangan Sumber Daya Manusia, Edisi Kedua, Cetakan Pertama, PT Rineka Cipta, Jakarta

Nitisemito, Alex S., 2004, Manajemen Personalia, Cetakan 9, Edisi Ketiga, Penerbit Ghalia Indonesia, Jakarta.

Robbins, S.P dan Timothy A. Judge. 2015. Perilaku Organisasi, Edisi 16. Jakarta: Salemba Empat.

Robbins, Stephen P., 1996. Perilaku Organisasi Konsep, Kontroversi, Aplikasi. Edisi Bahasa Indonesia, Jakarta: Penerbit PT. Prenhalhindo.

Robbins, Stephen P, 1995. Perilaku Organisasi, jilid 1, Edisi Bahasa Indonesia, cetakan pertama, diterjemahkan oleh Hadyana Pujaatmaka dan Benyamin Molan, Jakarta.

Rivai, Veithzal. 2009. Kepemimpinan dan Perilaku Organisasi. Edisi Kedua. Cetakan Kedua. Penerbit PT. Raja Grafindo Persada. Jakarta.

Rivai, Veitsal, 2005, Manajemen Sumbar Daya Manusia untuk Perusahaan dari Teori ke Praktek PT Raja Grafindo Persda, Jakarta.

Sedarmayanti. 2007. Manajemen Sumber Daya Manusia: Reformasi Birokrasi dan Manajemen Pegawai Negeri Sipil. Cetakan Pertama. Penerbit PT.Refika Aditama. Bandung.

Sedarmayanti, 2004, Sumber Daya Manusia dan Produktivitas Kerja, CV.Mandar Maju, Bandung.

Santoso, Singgih, 2002, Statistik Parametrik, Cetakan Pertama, Penerbit Elex Media Komputindo, Jakarta

Sutrisno, Edy. 2010. Manajemen Sumber Daya Manusia. Edisi Pertama. Cetakan Pertama. Penerbit Kencana. Jakarta.
Susanto, AB, 2000, Konsep Budaya Perusahaan, The Jakarta Consulting Group, Jakarta

Siagian, Sondang. 1998. Organisasi Kepemimpinan dan Perilaku Administrasi. Jakarta : CV Haji Masagung

Sarwoto, Bedjo, 1991. Dasar - dasar Organisasi Manajemen. Cetakan Keempat. Jakarta : Ghalia Indonesia.. Soegiyono, 2007. Metode Penelitian Bisnis. Bandung : Alfabeta, CV.

Sujadi, 2007, Pengaruh Iklim Kerja dan Motivasi Kerja terhadap Kinerja Guru SMP Alumni Diklat PTBK di Bangkalan, Un-published, Tesis Program Pascasarjana, Unesa Surabaya

Sumanto, 2014, Teori dan Aplikasi Metode Penelitian, Cetakan Pertama. Center of Academic Publishing Service : Jakarta

Ujianto, dkk. 2018. Pedoman Penulisan Tesis Program Magister Manajemen Sekolah Tinggi Ilmu Ekonomi Pancasetia Banjarmasin. STIE Pancasetia : Banjarmasin Umar, Husein. 2008. Riset Sumber Daya Manusia Dalam Organisasi, Cetakan Keenam, Penerbit PT. SUN, Jakarta.

Winardi. 2008. Kepemimpinan Dalam Manajemen, Cetakan Kedua, Penerbit PT. Rineka Cipta, Jakarta.

Wibowo, 2009. Manajemen Kinerja, Penerbit PT. Raja Grafindo Persada, Jakarta. 